\title{
Laicidad y libertad religiosa en la jurisprudencia de la Corte Europea de Derechos Humanos: una convivencia necesaria y difícil
}

\author{
Víctor J. Vázquez Alonso \\ Profesor de Derecho Constitucional \\ Universidad de Sevilla
}

Recibido: 26.09 .08

Aceptado: 22.10 .08

\begin{abstract}
Resumen: La regulación jurídica de las relaciones entre el Estado y las Iglesias, o entre el Estado y el fenómeno religioso, está íntimamente relacionada en los países europeos con la historia nacional de cada país. Por este motivo, el Tribunal Europeo de Derechos Humanos, una jurisdicción necesariamente comprometida con la integración de las diferencias nacionales, ha sido especialmente respetuoso con el «margen de apreciación nacional» de las autoridades estatales a la hora de regular la gestión del pluralismo religioso. Ahora bien, esto no ha impedido la afirmación por parte del TEDH del valor objetivo de la libertad religiosa, ni la asunción de la laicidad del Estado, como un elemento consustancial al sistema democrático, y por lo tanto, como un valor integrante del orden público europeo. El hecho de que la laicidad haya sido erigida en uno de los valores de la Convención exige plantearnos cuáles son los contornos jurídicos de este principio. En definitiva, de qué laicidad estamos hablando. En este artículo, se defenderá que, dentro del ámbito del Convenio, y tomando en consideración la importancia objetiva de la libertad religiosa, la laicidad ha de entenderse como un principio indeclinable dentro del Estado de Derecho, pero también en un sentido de mínimos, y por lo tanto, en ningún caso asimilable, a los concretos perfiles que adquiere este principio en ordenamientos como el francés o el turco, donde, según circunstancias históricas y sociales, el principio de laicidad legitima determinadas ingerencias en la manifestación del derecho a la libertad religiosa.
\end{abstract}

Palabras clave: Tribunal Europeo de Derechos Humanos, margen de apreciación nacional, libertad religiosa, laicidad.

Abstract: In Europe, legal regulation of the relationship between the State and the churches, or between the State and the religious phenomenon, is closely linked to the national history of each country. Therefore, the European Court of Human Rights, a jurisdiction that is necessarily committed to the integration of national disparities, has been especially respectful with the "margin of national appreciation» of State authorities when it comes to regulate the management of religious pluralism. Nonetheless, this has not prevented the ECHR from stating the objective value of religious freedom, and the assumption of State secularism as an inherent element of the democratic system, and thus as a value that integrates the European public order. The fact that secularism has been erected as one of the Convention values calls for a better definition of the juridical outline of this principle, that is, to determine what is meant as secularism. In this article we purport that, within the Convention scope, and considering the objective relevance of reli- 
gious freedom, secularism should be understood both as a principle inalienable of the State based on the rule of law, and as a minimum threshold, and hence it is inassimilable to the specific profiles of this principle in the French and Turkish legal systems, in which the principle of secularism legitimates certain infringements of the right to religious freedom on historical and social grounds.

Key words: European Court of Human Rights, margin of national appreciation, religious freedom, secularism.

Sumario: 1. El Tribunal Europeo de Derechos Humanos. Jurisdicción e integración nacional.-2. Diversidad de modelos Iglesia Estado y valor objetivo de la libertad de creencias en el ámbito del Convenio Europeo de Derechos Humanos.-3. La garantía del pluralismo religioso en la jurisprudencia del TEDH. Entre la protección del derecho y la permisividad de las ingerencias. - 4. La laicidad elevada a valor del Convenio Europeo de Derechos Humanos. ¿Qué laicidad?-5. A modo de conclusión.

\section{El Tribunal Europeo de Derechos Humanos. Jurisdicción e integra- ción nacional}

No parece muy arriesgado decir que el acervo cultural común entre los países firmantes del Convenio Europeo de Derechos Humanos ha sido una de las claves del buen funcionamiento de la que puede decirse es la institución estrella en lo referido a la protección de derechos en el ámbito supranacional ${ }^{1}$. Este sedimento cultural compartido y a buen seguro abonado por la trágica historia de guerras, enfrentamientos y miserias que ha albergado la geografía europea hasta fechas no muy lejanas ${ }^{2}$, ha servido sin duda para que

${ }^{1}$ El propio preámbulo del Convenio hace un guiño expreso a la herencia cultural europea como fuente de inspiración del texto: «Resueltos, en cuanto Gobiernos de Estados europeos animados de un mismo espíritu y en posesión de un patrimonio común de ideales y de tradiciones políticas, de respeto a la libertad y de preeminencia del Derecho, a tomar las primeras medidas adecuadas para asegurar la garantía colectiva de algunos de los derechos enunciados en la Declaración Universal».

${ }^{2}$ Los discursos radiofónicos del poeta T. S. Eliot sobre «la unidad de la cultura europea» emitidos en Alemania tras la Segunda Guerra Mundial, son un extraordinario ejemplo de cómo la experiencia de un «periodo de inusitada destructividad» en Europa, trajo consigo una búsqueda intelectual de los elementos culturales comunes sobre los que construir un ideal de integración europeísta, enriquecido y respetuoso con las diferencias nacionales. Para el poeta: «La salud cultural de Europa requiere dos condiciones: que la cultura de cada país sea única y que las distintas culturas reconozcan la relación que hay entre ellas, de modo que cada una sea susceptible de recibir la influencia de las demás. Y esto es posible porque hay un elemento común en la cultura europea, una interrelación en la historia del pensamiento, los sentimientos y el comportamiento, un intercambio de arte e ideas». Vid. T. S. Eliot, La unidad de la cultura europea, Madrid, 2003. 
la integración de las distintas soberanías en un orden jurisdiccional común se haya podido llevar a cabo con la dosis de generosidad nacional necesaria, para que la tutela internacional de los derechos fundamentales sea hoy, en el ámbito europeo, algo más que un ideal coyuntural y difuso ${ }^{3}$. Los años de funcionamiento de los órganos de Estrasburgo han servido igualmente para edificar un léxico europeo de derechos fundamentales, un ius commune continental de las libertades, al que han sido permeables las jurisdicciones nacionales, contribuyendo a la creación de una cierta cultura constitucional común ${ }^{4}$, sobre la que sin duda resulta más plausible la eficacia material del Convenio, más allá de los singulares pronunciamientos del Tribunal Europeo de Derechos Humanos (en adelante TEDH, o Tribunal). Aun así, el alcance del sistema europeo de derechos humanos tiene sus límites, y sobre él operan, como destaca Carrillo Salcedo, factores de «fragmentación y relativismo» que no pueden ser ignorados ${ }^{5}$.

Y es que pese a las cercanías y a los «acercamientos», el conteniente europeo es también un territorio de viejas naciones, y culturas políticas y jurídicas dispares ${ }^{6}$. Es por ello por lo que la suerte de su integración pasa en cualquiera de sus experimentos supranacionales, por mantener el difícil equilibrio entre el respeto a las necesidades democráticas puntuales, las tra-

${ }^{3}$ En este sentido, en reiteradas ocasiones, el filósofo Jürgen Häbermas ha interpretado el éxito de los distintos ámbitos europeos de integración supranacional como una constatación del potencial integrador del derecho en el ámbito político, aun cuando tal integración se lleva a cabo sobre colectivos nacionales diferenciados. Vid. J. HäBERMAS, Facticidad y Validez, Madrid, 1998, pp. 620-622. De igual modo en La inclusión del otro, Barcelona, 1999, pp. 138-143.

${ }^{4}$ Sobre esta vinculación entre constitución y cultura es referencia obligada la obra de P. HÄBERLE, Teoría de la constitución como ciencia de la cultura, Madrid, 2000; en nuestra doctrina véase el trabajo de J. L. CASCAJO CASTRO, «La Cultura Constitucional», en M. A. Ramiro Aviles, G. PeCes-BArba (coords.), La Constitución a examen: un examen: un estudio académico 25 años después, Madrid, 2004, pp. 107-126.

${ }^{5}$ Llama la atención el autor en este sentido sobre el dato de que todo el sistema de protección de derechos humanos europeo no está creado sino a través de tratados, con lo cual «el consentimiento de los Estados soberanos va a condicionar el alcance de las obligaciones jurídicas». En este sentido, constituyen en su opinión claros límites al sistema, el hecho de que no todos los Estados miembros del Consejo de Europa vinculados al Convenio están obligados por los distintos Protocolos adicionales normativos que han ampliado la lista de derechos y libertades; y en segundo lugar, porque muchos de los Estados han formulado reservas y declaraciones interpretativas que irremediablemente dotan de subjetividad a las obligaciones jurídicas asumidas por los Estados. Vid. J. A. Carrillo Salcedo, «El Convenio Europeo de Derechos Humanos», en La Protección Internacional de los Derechos Humanos en los Albores del Siglo XXI, Deusto, 2003, pp. 403.

${ }^{6}$ Vid. M. Delmas-MarTy, «Pluralisme et traditions nacionales», en VV. AA., Quelle Europe pour les droits de l'homme? La Cour de Strasburg et la réalisation d'une union plus étroite, Bruselas, 1996. 
diciones constitucionales de los Estados Miembros, y el ejercicio efectivo de sus competencias por parte de los organismos europeos ${ }^{7}$.

A este respecto, toda una amalgama de principios formales, algunos de ellos previstos originariamente en el Convenio, como «la necesidad de la medida en una sociedad democrática»; y otros consolidados por la jurisprudencia, como el «principio de proporcionalidad», el «principio de subsidiariedad», o el denominado «margen de apreciación nacional», han servido al Tribunal para orientar esta difícil operación de funambulismo a partir de la cual se integra lo nacional en el seno de una jurisdicción de las libertades a nivel europeo ${ }^{8}$.

La armonización entre lo nacional y lo supranacional requiere una especial prudencia por parte de los órganos de Estrasburgo, necesariamente al amparo de un margen de discrecionalidad judicial más amplio del que disfrutan las jurisdicciones constitucionales nacionales. La importancia mediadora inherente a toda hermenéutica jurisprudencial, de cara a favorecer la comunicación y el consenso ${ }^{9}$, se agrava cuando se trata de integrar distintas realidades nacionales en una jurisdicción común. Las potencialidades interpretativas del Convenio no son en este contexto sino potencialidades inclusivas, que facilitan una cierta discrecionalidad para favorecer la integración. Como ha señalado Carrillo Salcedo, al amparo de este ámbito de valoración, la jurisdicción europea del TEDH ha oscilado entre «una tendencia de autocontrol judicial», que acentúa el carácter subsidiario de su jurisdicción, y que

${ }^{7}$ Como ha reiterado Häberle, todo texto jurídico que albergue una importante carga valorativa, como sin duda lo hace el Convenio Europeo de Derechos Humanos, es también el sedimento de una cultura común. Esta comunidad de valores, si bien en gran medida es clave para la eficacia jurídica del texto, puede también dificultar la integración de las distintas subculturas nacionales, si no goza de dinamismo y apertura interpretativa. Vid. Pluralismo y constitución, Madrid, 2002, p. 89.

${ }^{8} \mathrm{La}$ importancia de estos principios como mecanismos de integración funcional de los Estados dentro de la jurisdicción de Estrasburgo, ha sido recientemente desarrollada en la doctrina española por el profesor Javier García Roca. Como señala el autor, la protección de los derechos en el ámbito del Convenio no puede entenderse al margen de la necesidad de «conjugar un intenso pluralismo de base territorial -más que la vieja soberanía absolutacon una integración europea a un tiempo prudente que puedan asumir las opiniones públicas de los Estados miembros». En este sentido, es inevitable que en determinadas materias especialmente sensibles, se plantee el conflicto de «¿Cuándo debemos avanzar en integración o respetar las diferencias nacionales?». Vid. J. GARCíA RoCA, «La muy discrecional doctrina del margen de apreciación nacional según el Tribunal Europeo de Derechos Humanos: soberanía e integración», Teoría y Realidad Constitucional, n. ${ }^{\circ} 20$, 2007, en especial pp. 120-131. Subrayando el potencial integrador del principio de subsidiaridad en el contexto constitucional europeo, es particularmente interesante el reciente trabajo de M. RoDRÍGUEZ-IzQUIERDO, Posibilidades constitucionales del principio de subsidiariedad, Granada, 2008. En especial, pp. 29-44.

${ }^{9}$ Vid., J. L. CASCAJO CASTRO, «La interpretación constitucional», Claves de la razón práctica, diciembre de 2003, p. 21. 
en virtud del margen de apreciación nacional ha sido permisiva con determinadas limitaciones a los derechos reconocidos; y una tendencia más favorable a la dimensión constitucional del Convenio, como instrumento de orden público europeo de derechos y libertades ${ }^{10}$.

Pero el respeto a los contextos nacionales, a aquello que necesariamente ha de pertenecer al ámbito de decisión de los Estados, en ocasiones, paradójicamente, no sólo es una fuente de excepciones a través de las cuales se permite la ingerencia estatal en un determinado derecho recogido en el Convenio; sino que, a su vez, los criterios reiterados en la admisión de determinadas ingerencias estatales en los derechos, en función de sus necesidades democráticas, pueden acabar consolidando principios generales no previstos originariamente en el Convenio, que legitiman la regulación restrictiva del ejercicio de determinados derechos en él garantizados. Al fin y al cabo, como toda jurisdicción final, el TEDH es fuente de derecho vivo, y es natural por tanto que, a pesar de su casuismo y especial discrecionalidad, la inercia jurisprudencial acabe por establecer nuevos parámetros a través de los cuales juzgar la adecuación al Convenio de las actuaciones de los Estados. Este tránsito lo podemos observar en el contexto relacionado de la protección del derecho a la libertad religiosa, y los distintos modelos de relación Iglesia-Estado existentes en el ámbito de aplicación del Convenio; en el cual la laicidad parece haber pasado de ser una circunstancia contextual que amparaba determinadas políticas estatales restrictivas de la expresión religiosa, a erigirse por el Tribunal en uno de los valores inherentes a la sociedad democrática que conforman el orden público europeo.

\section{Diversidad de modelos Iglesia-Estado y valor objetivo de la libertad de creencias en el ámbito del Convenio Europeo de Derechos Humanos}

Si una cuestión resulta especialmente sensible o permeable a la historia nacional de cada Estado en materia constitucional, ésta es sin duda la de las relaciones entre el Estado y las distintas Iglesias ${ }^{11}$. Así, en Europa, los dis-

${ }^{10}$ Vid. J. A. Carrillo SAlCEDo, «El Convenio Europeo de Derechos Humanos», op. cit., pp. 423-427. Esta tensión entre la subsidiaridad del Convenio y su tendencia evolutiva a imponer una uniformidad en el tratamiento de los Derechos fundamentales entre los Estados miembros es el objeto de la extensa obra de E. KastanAs, Unité et diversité: Notions autonomes et marge d'appréciation des Etats dans la jurisprudence de la Cour européenne des droits de l'homme, Bruselas, 1996.

${ }^{11}$ Es necesario recordar a este respecto como el propio proceso de integración de la Unión Europea ha sido siempre sensible a la pluralidad de tradiciones en este ámbito. El Tratado de Ámsterdam ya declaraba que «La Unión europea respeta y no prejuzga el estatuto reconocido, en virtud del derecho nacional, a las iglesias las asociaciones o comunidades religiosas en los Estados miembros». Sobre este punto véase O. CELAdOR Angón, «Notas para una interpretación sistemática del artículo 6 del Tratado de la Unión Europea en materia de libertad religiosa», Derechos y libertades, n. ${ }^{\circ} 12,2004$, pp. 141-178. 
tintos modelos varían desde las viejas Iglesias de Estado (Inglaterra, Dinamarca, Grecia, Finlandia), hasta diversos sistemas de separación (Francia, Irlanda o, en lo que respecta al ámbito del Consejo de Europa, Turquía), y experimentos de colaboración o cooperación de distinta intensidad (Alemania, Bélgica, Italia, España, Austria, Portugal) ${ }^{12}$.

Desde una perspectiva constitucional, resulta por lo tanto imposible reducir a un patrón institucional común la relación del Estado con la religión en el continente europeo. Del mismo modo, debemos añadir que cualquier tipo de clasificación o subdivisión que se quiera hacer de los modelos europeos resultará falible. En este sentido, hay que hablar necesariamente de «modelos impuros», ya que, incluso dentro de estructuras institucionales comunes, el desarrollo concreto que éstas adquieren está expuesto a factores de cambio y a distintas tendencias evolutivas, generalmente orientadas hacia una mayor secularización de las instituciones y del ordenamiento jurídico, pero no siempre con la misma intensidad, ni a través de los mismos mecanismos ${ }^{13}$.

Como el propio Tribunal ha reconocido, y en buena medida ha puesto de manifiesto el dilatado debate sobre la pertinencia de llevar a cabo un reconocimiento explícito de las raíces cristianas de la Unión en la Constitución europea ${ }^{14}$,

${ }^{12}$ Encontramos un estudio particularmente detallado de las simetrías y asimetrías existentes en el modelo de relación del Estado con las Iglesias entre los distintos países europeos en la obra de M. D. CHARLIER-DAGRAS, La lä̈cité français à l'épreuve de l'integration europeénne. Pluralisme et convergentes, París, 2002, en especial, pp. 205 y ss.; igualmente, pueden verse las páginas que dedica al estudio comparado de la regulación de la libertad religiosa en el ámbito europeo P. Pulido AdRAGaO, en A Liberdade Religiosa e o Estado, Coimbra, 2002, en especial, pp. 130-275; y el trabajo compilado por J. ROBERTS, «Les Relations des Églises et de l'Etat en Europe», La liberté religieuse et la Convention européene des droits de l'homme, Actes du colloque du 11 décembre 2003 organisé à l'auditorium de la Maison du barreau par l'Istitut de formation en droits de l'homme du Bareu de Paris, et l'Ordre des avocats à la tour de Paris, París, 2004. pp. 25 y ss. Desde el punto de vista dinámico, resulta de especial interés la distinción que realiza entre los distintos procesos de desconfesionalización en Europa, F. CHAMPION, «Entre laïcisation et sécularisation, Des rapports Église-État dans l'Europe communautaire», Le debat, 77, 1993, pp. 46 y ss.; igualmente véase el trabajo de S. CECCANTI, Una Libertá comparata. Libertá religiosa, Fondamentalismi e Societá Multietniche, Bolonia, 2001, en especial, pp. 9-33. En nuestra doctrina eclesiástica, es destacable la obra de A. FERNÁNDEZCoronado González, J. A. Rodríguez García; M. Murillo Muñoz; P. C. Pardo Prieto, El Derecho de la libertad de conciencia en el marco de la Unión Europea, Madrid, 2002.

${ }^{13}$ Véase en este sentido, el trabajo de I. IBAn, y S. FerRARI, Derecho y Religión en Europa occidental, Madrid, 1998; o J. RoBerT, «Les relations des Églises et de L'Etat en Europe», en VV. AA., La liberté religieuse et la Convention européenne des droits de l'homme, Bruselas, 2004.

${ }^{14}$ Es una cita obligada en esta materia el ensayo J. J. WeILER, Una Europa Cristiana, Ensayo exploratorio, Madrid, 2003. Del mismo modo, resulta especialmente ilustrativo de la disparidad de puntos de vista que caracterizó este debate, el diálogo mantenido por este autor con Francisco Rubio LlORENTE en la Revista de Occidente, n. ${ }^{\circ} 271$, diciembre 2003, pp., 87 y ss., y que sirve de epílogo a la edición española del libro antes citado. 
tampoco es posible discernir a través de Europa una concepción uniforme del significado de la religión en la sociedad ${ }^{15}$; y mucho menos, podríamos añadir nosotros, de la incidencia que puedan tener las motivaciones o propósitos de carácter religioso en los procedimientos de decisión democrática en los diferentes Estados ${ }^{16}$. En un principio, estas disparidades han hecho que necesariamente el TEDH no haya mostrado preferencia valorativa por un determinado modelo de relación entre la Iglesia y el Estado. La dimensión institucional de la religión ha permanecido, al menos en principio, al margen de la incumbencia de Estrasburgo.

Sin embargo, aunque no sin cierta demora, el Juez de Estrasburgo sí ha sido particularmente explícito a la hora de subrayar la importancia objetiva del derecho a la libertad religiosa en el ámbito público a través de su jurisprudencia ${ }^{17}$. En la emblemática sentencia Kokkinakis c. Grecia, la primera en la cual el Tribunal resuelve con una condena al Estado una demanda basada en la vulneración del artículo 9 de la Convención, se precisa «que la libertad de pensamiento, de conciencia y de religión, representan uno de los cimientos de una sociedad democrática en el sentido de la Convención». Esta libertad figura por tanto «entre los elementos más esenciales de la identidad de los creyentes y de su concepción de la vida, pero es también un bien preciado para los ateos, los agnósticos, los escépticos, y los indiferentes. Es condición del pluralismo consustancial a una sociedad libre».

En este sentido y de forma lógica, la vocación integradora de la jurisprudencia del Tribunal, y el respeto tanto por el distinto significado de la religión en la sociedad, como por la diversidad de modelos de relación entre la

Dentro de la doctrina francesa, donde la mención explícita a las raíces cristianas de la Unión despertó más suspicacias, son particularmente equilibradas las reflexiones que con la vista puesta en futuras ampliaciones de los Estados miembros y en el cambio de paradigma religioso experimentado en la Unión desde su nacimiento, realiza el profesor J. ROBERT, en «Les relations des Églises et de l'Etat en Europe», op. cit., pp. 29-40.

${ }^{15}$ Como reconoce expresamente el Tribunal en la sentencia Otto-Preminger-Institut $c$. Autriche, 20 septembre 1994, §50: «Comme pour la morale, il n'est pas possible de discernir à travers l'Europe une conception uniforme de la signification de la religion dans la societé».

${ }^{16}$ Un ejemplo de ello podría ser el Estado de Irlanda, donde pese a que puede afirmarse que rige un modelo constitucional de separación entre la Iglesia y el Estado, la influencia de la moral católica en la regulación jurídica de materias como el aborto ha sido más que evidente.

${ }^{17}$ La prudencia del Tribunal a la hora de respetar la gestión jurídica estatal de la religión, hizo sin duda que se retrasasen las sanciones del tribunal en aplicación del artículo 9 para determinar la violación del convenio. Cierta doctrina llegó incluso a sugerir, en relación con el artículo 9, que «était illusorie, insusceptible de connaître une quelconque sanction juridictionalle dans le cadre européen». Vid. F. BERGER, H. LABAYLE, F. SudRE, «Droit administratif et Convention européenne des droits de l'homme», Revue François du Droit Administrative, 1991, pp. 848. Citado por A. DEBET, «Signes Religeux et Jurisprudence Européenne», en La Laïcité, Archives de Philosophie du Droit, París, 2005, p. 225. 
Iglesia y el Estado existentes en los países parte del Convenio, no ha sido óbice para que haya antepuesto de forma general este respeto por las características nacionales en el tratamiento del fenómeno religioso a la garantía de la libertad religiosa. Es un buen ejemplo de ello la condena al Estado sueco por obligar a un ciudadano finlandés no residente en Suecia a contribuir con sus impuestos a la Iglesia Luterana Sueca, sin que él mismo profesase esta creencia ${ }^{18}$; e igualmente, el affaire Buscarini y otros c. San Marino, en el cual el Tribunal atendió a la demanda de dos parlamentarios que recurrían frente a la obligación de jurar los Evangelios requerida para la toma de posesión de su cargo, priorizando la garantía de su libertad religiosa, sobre la tradición católica de la Serenísima República de San Marino ${ }^{19}$. La ya aludida condena al Estado griego en el caso Kokkinakis c. Grecia, por la represión penal de los actos de proselitismo religioso llevados a cabo por un testigo de Jehová ${ }^{20}$, es también significativa de cómo el Tribunal, pese a no prejuzgar el estatuto jurídico de la Iglesia Ortodoxa en Grecia, impone límites a las medidas restrictivas de la libertad religiosa ${ }^{21}$ que pudieran ser tomadas con el objetivo de salvaguardar la confesionalidad sociológica del país. Del mismo modo, ante la negativa del Estado griego a autorizar lugares públicos de culto, el Tribunal ha declarado en distintas ocasiones que el Convenio impone una obligación de neutralidad al Estado, en el sentido de que excluye cualquier apreciación estatal de la legitimidad de las creencias ${ }^{22}$. Quizás otra de las decisiones más expresivas de esta vinculación trazada por parte del Tribunal entre la protección de la libertad religiosa y la neutralidad estatal frente a las creencias de los ciudadanos, la constituye el conocido affaire

${ }^{18}$ TEDH Darby c. Suède, 23 de octubre 1990. Una condena que se resuelve a través de la aplicación del artículo 14 del Convenio, y no del 9, ya que la legislación sueca preveía una exención fiscal para los residentes que no fueran miembros de la entonces Iglesia oficial del Estado, pero no para los no residentes.

${ }^{19}$ TEDH Buscarini et autres c. San Marino, 18 de febrero de 1999. Concretamente el Gobierno de San Marino subrayaba la importancia de salvaguardar los valores republicanos en toda democracia. Unos valores, destaca en su defensa, que en San Marino están estrechamente ligados a su historia y tradición cristiana. Para lo cual no duda en recordar el dato de que esta pequeña República europea fue fundada por un santo.

${ }^{20}$ Como es sabido, en esta sentencia el TEDH entiende que un simple acto de proselitismo en condiciones de normalidad, frente a una persona adulta y en pleno uso de su libertad, no justifica ninguna restricción en la libertad del actor, en aras de salvaguardar los principios de la sociedad democrática. El Tribunal realiza en la sentencia la distinción entre lo que puede considerarse un «proselitismo propio», esencial a la religión cristiana, y otro «impropio», de carácter agresivo, embaucador o destructivo de la personalidad, que sería incompatible con el respeto de la libertad de conciencia de los individuos, y contra el cual serían legítimas determinadas medidas de represión.

${ }^{21}$ El Tribunal consideró en este sentido que la enseñanza de la religión forma parte del derecho a la libertad religiosa.

${ }^{22}$ SstedH Manoussakis y ot. c. Grèce, 26 de septiembre de 2006; Pentidis y ot. c. Grèce, 9 de junio de 1997; y Tsavachidis y ot. Grèce, 21 de enero de 1999. 
Hoffmann c. Austria, en el cual el Tribunal estima que carece de cualquier «justificación objetiva y razonable» la decisión tomada por los tribunales de un país mayoritariamente católico como es Austria de privar a una madre divorciada de la custodia de su hijo por el hecho de que ésta se había convertido a la religión de los testigos de Jehováa ${ }^{23}$.

A pesar de que en decisiones como las citadas la neutralidad del Estado con respecto a las distintas religiones constituye un valor subyacente a la jurisprudencia del Tribunal, lo cierto es que en un contexto como el europeo donde las religiones mayoritarias gozan tradicionalmente de beneficios institucionales y materiales por parte de los Estados, la dimensión igualitaria de la libertad religiosa sólo puede ser garantizada en el ámbito del Convenio con importantes matices. Y es que el respeto a los diversos modelos de relación entre la religión y el Estado, requiere una necesaria condescendencia con las diferencias de trato existentes entre unas comunidades religiosas y otras $^{24}$. Si echamos una mirada sincera al derecho de las religiones en el ámbito europeo, podemos comprobar cómo, si bien éste ya no discrimina por la vía de prohibir, lo sigue haciendo por la vía de subvencionar o promocio$\operatorname{nar}^{25}$. La aplicación de la lógica del Estado Social a una libertad como la religiosa, o lo que es lo mismo, la configuración de la libertad religiosa como

${ }^{23}$ TEDH Hoffmann c. Autriche, 23 de junio de 1993.

${ }^{24}$ De esta opinión es Pablo Santaolaya, quien trae a colación una serie de sentencias del Tribunal que ponen de manifiesto cómo el respeto al margen de apreciación nacional ha impedido la construcción por parte del Tribunal de un estándar mínimo de la libertad religiosa. La primera de ellas sería la ya aludida Darby c. Suecia en la que el Tribunal afirma indirectamente la adecuación al convenio de la existencia de un Tributo religioso en beneficio de la Iglesia nacional, siempre que se posibilite la exoneración de los no pertenecientes a ésta. En segundo lugar, destaca la inadmisión a trámite por parte de la Comisión de un recurso presentado contra España por la Iglesia Bautista «El Salvador» en el que se denunciaban los privilegios fiscales exclusivos de los que disfrutaba la Iglesia católica por sus lugares de culto. En último lugar, Santaolaya alude a dos sentencias en las cuales el Tribunal ha entendido conformes con el Convenio sendas limitaciones de la libertad de expresión dirigidas a salvaguardar el sentimiento religioso de la mayoría de la comunidad, los casos Otto Preminger Institut c. Austria, de 20 de septiembre de 1994, y Wingrove c. Reino Unido de 25 de noviembre de 1996. Vid. P. SANTAOLAYA, «Sobre el derecho a la laicidad (Libertad religiosa e intervención de los poderes públicos», en Revista catalana de dret públic, $\mathrm{n}^{\circ}$ 33, pp. 58-61. Analizando esta misma jurisprudencia, también para evidenciar la viabilidad de las Iglesias de Estado dentro del Convenio, véase también M. D. ChARLIER-DAGRAs, La laïcité français à l'épreuve de l'integration europeénne. Pluralisme et convergentes, op. cit., pp. 345-346.

${ }^{25}$ Tomando prestada la certera expresión de PRIETO SANCHÍs, autor al que básicamente seguimos en este párrafo. L. PRIETO SANCHís, «Minorías, respeto a la disidencia e igualdad sustancial», DOXA 15-16, 1994, p. 378. Sobre la compleja dimensión prestacional de la libertad religiosa en el derecho español y su incidencia en el principio de igualdad, véanse las páginas que a ello dedica Abraham Barrero Ortega, en su excelente monografía A. Barrero Ortega, La libertad religiosa en España, Madrid, 2006, pp. 137 y ss. 
una «libertad asistida» a partir de criterios histórico-cuantitativos, conduce irremediablemente a situaciones de desigualdad para las minorías religiosas y, en gran medida, invierte la lógica de la labor promocional del Estado.

En este sentido, desde el punto de vista de los principios de neutralidad y de igualdad, la vigencia del privilegio en materia religiosa constituye sin duda una de las contradicciones constitucionales internas de muchos de los Estados europeos ${ }^{26}$, sin que la secularización de las sociedades europeas, ni su paulatina recomposición pluralista o multicultural, hayan afectado en gran medida a su vigencia. El viejo vínculo entre religión y nación, permanece residualmente en los ordenamientos a través de estatutos jurídicos privilegiados de relación con el Estado para determinadas confesiones, y su continuidad no parece que vaya a ser enturbiada por la jurisprudencia de un órgano supranacional comprometido con un proceso de integración funcional realista ${ }^{27}$.

Como ha señalado Charlier-Dagras, el Tribunal «no presupone ninguna antinomia entre el reconocimiento religioso y la garantía de la libertad religiosa ${ }^{28}$, sino que simplemente vincula la garantía de esta libertad al com-

${ }^{26}$ El reconocimiento constitucional del concordato y la pasividad histórica de la democracia-cristiana en el proceso de desconfesionalización del país han hecho sin duda de Italia el país donde la doctrina ha sido mas crítica a la hora de denunciar que a partir de la mayor tradición y difusión de un credo se justifique un privilegio estatal sobre otras religiones concurrentes o minoritarias. Podemos hacer referencia a distintos trabajos en este sentido. F. Rimoli, «Laicità» (dir. Cost), in Enc. Dir. p. 2; R. BIN, «La libertá de Religione», en VV. AA., I soggetti del pluralismo nella giurisprudenza costituzionale, a cura di Roberto Bin e Cesare PINElli. Turín, 1996; N. BobBio, en Laicità. Domande e risposte in 38 interviste, Comitato torinese per la laicità della scuola (ed.), Turín, 2003, p. 57.

${ }^{27} \mathrm{Al}$ aludir a la «integración funcional» seguimos la terminología «Smendiana» que trae a colación Javier García Roca para referirse al tema que nos ocupa, en su prefacio al libro colectivo, J. García Roca, P. SAnTaOlaya (Coords.), La Europa de los derechos. El Convenio Europeo de Derechos Humanos, Madrid, 2005. pp. 13-47, en especial. pp. 33-37. En este mismo libro, podemos encontrar una certera explicación de las dificultades que marcan la aplicación jurisprudencial del principio de igualdad con respecto al derecho a la libertad religiosa en el ámbito del Consejo de Europa, en artículo de Alejandro Torres Gutiérrez dedicado a la libertad de pensamiento, conciencia y religión. Creemos conveniente en este sentido reproducir el siguiente párrafo: «el TEDH ha actuado admitiendo sumamente amplios márgenes de apreciación en las intervenciones estatales incluida la posibilidad de trato diferenciado para las distintas confesiones, tanto desde el punto de vista de la libertad religiosa como del principio de igualdad, siempre que no implique un obstáculo para la profesión de la propia religión o no derive en discriminación, de forma que si bien el Estado ha de ser imparcial con relación a las confesiones religiosas de los individuos, no tiene por qué serlo con relación a las confesiones en las que éste se organiza». A. TORRES GuTIERREZ, «La libertad de pensamiento, conciencia y religión», La Europa de los derechos..., op. cit., pp. 511-512.

${ }^{28}$ M. D. Charlier-Dagras, La laïcité français à l'épreuve de l'integration europeénne. Pluralisme et convergentes, op. cit., en especial, p. 345. 
promiso del Estado con el principio de neutralidad, entendido éste en sentido débil. En realidad, el Tribunal europeo, al igual que el Tribunal Constitucional español ${ }^{29}$, y en ciertas sentencias, en las que aplica el denominado Coertion Test, la propia Corte Suprema de los Estados Unidos ${ }^{30}$, ha identificado el contenido del principio de neutralidad con la simple no coerción de la libertad de religión, y no con un tratamiento igualitario de las distintas manifestaciones de la libertad religiosa por parte del Estado, y la inexistencia de vínculos institucionales o simbólicos entre el Estado y las confesiones. Y ello porque la neutralidad en sentido estricto requiere previamente, como pone de manifiesto la doctrina y la propia experiencia histórica francesa, la separación entre el Estado y las Iglesias, entendida ésta como el no reconocimiento ni financiación por parte del Estado de ningún culto ${ }^{31}$, una circunstancia que salvo las excepciones laicas de Francia y Turquía, no se da en ninguno de los países que forman parte del Convenio.

Por lo tanto, las autoridades europeas no han asumido la laicidad en su sentido político originario ${ }^{32}$, como presupuesto del ejercicio de la libertad religiosa en condiciones de igualdad ${ }^{33}$. Las Iglesias de Estado son, en este sentido, compatibles con el Convenio Europeo de Derechos Humanos. Sin embargo, paradójicamente, no ya al juzgar la pervivencia de residuos de confesionalidad que quiebran la igualdad religiosa frente al Estado, sino al enjuiciar las medidas tomadas por un Estado laico como Turquía para combatir las amenazas de «deslaicización» del espacio público, el Tribunal, como veremos a continuación, ha erigido el principio de laicidad, entendido

${ }^{29}$ En este sentido, el Tribunal español ha entendido que si bien un militar no puede verse obligado a participar en actos de inequívoco contenido religioso, el principio de neutralidad no impide al Estado la participación en ceremonias de naturaleza religiosa. Vid. SSTC $177 / 1996$ y $101 / 2004$.

${ }^{30}$ Vid. Lee v. Weisman, 505 U.S. 577, 593 (1992). Esta interpretación de la Establishment Clause ha sido avalada por cierta doctrina, puede verse en este sentido A. ScHWARZ, «No imposition of Religion: The Establishment Clause Value», 77 Yale Law Review, 1968. M. McConnel, «Coertion: The Lost Element of Establishment», 27 William and Mary Law Reivew, 1985/1986.

${ }^{31}$ Vid. M. BARBIER, La Laïcité, París, 1995.

${ }^{32}$ El cual, podemos permitirnos decir, sería aquel que el principio adquiere en la experiencia histórica francesa J. BAUBEROT, Historie de la laïcité en France, París, 2000; E. Poulat, Liberté, laïcité. La guerre des deux France et le principe de modernité, París 1987; J. RIVERO, «De l'ideologie á la règle de droit: La notion de laïcité dans la consideration doctrinal», en La Laïcité, París, 1960.

${ }^{33}$ Curiosamente, un país donde la laicidad se identifica con la propia forma republicana de gobierno, como es Francia, fue obligado por la antigua Comisión Europea de Derechos Humanos, a extender, en virtud del artículo 14 del Convenio, las ventajas fiscales dispensadas por el derecho francés a las «asociaciones para el culto» a la «Union des Athées Français». Resulta interesante la crítica a la legislación fiscal francesa que beneficia a las asociaciones dedicadas exclusivamente al culto, que realiza O. SCHRAMECK, en «La fin de la laïcité fiscale», La actualité juridique-droit administrative, 20 avril 1988. 
éste en un sentido elemental y por lo tanto compatible con la pervivencia de residuos de confesionalidad en los Estados, en uno de los valores integrantes del orden público europeo.

\section{La garantía del pluralismo religioso en la jurisprudencia del TEDH. Entre la protección del derecho y la permisividad de las ingerencias}

A pesar de la generosidad de los términos a partir de los cuales el Tribunal alude a la libertad de religión en su jurisprudencia, y de la amplitud con la cual el derecho viene consagrado en el art. 9 del Convenio, en términos generales, el Juez de Estrasburgo, lejos de consolidar una concepción hipertrofiada de la libertad de religión, ha terminado por desarrollar una protección de este derecho cuya intensidad podríamos calificar de «perfil bajo» ${ }^{34}$. La razón de ello la encontramos tanto en el respeto a la modelos de relación Iglesia-Estado vigentes en los países miembros del Convenio, como, sobre todo, en la necesidad de evitar poner en peligro las opciones legislativas mantenidas por los Estados de cara a integrar y regular la convivencia equilibrada del pluralismo religioso y, también, en la especial consideración que el Tribunal ha concedido a las prevenciones estatales dirigidas a impedir la «deslaicización» del ámbito público, o a limitar y controlar la expresión del fundamentalismo religioso.

Como destaca De Salvia, a través de la jurisprudencia sobre el art. 9 del TEDH, puede comprobarse claramente cómo el Tribunal, desde el inicio, ha tomado en consideración que el propio pluralismo religioso consustancial al modelo europeo de sociedad democrática requiere, a su vez, una regulación de la expresión de ese pluralismo en el ámbito público ${ }^{35}$. Usando la terminología empleada por Häberle, podríamos decir que el Tribunal, desde el inicio, ha entendido que, entre «las tareas del pluralismo» asumidas por los Estados democráticos, se encuentra la de conciliar los intereses de las diversas religiones que coexisten en sus fronteras, y que esta tarea requiere, en ciertos casos, ejecutar sobre una libertad pública como la religiosa «las limitaciones necesarias para asegurar el respeto a las convicciones de cada uno».

La asunción de esta exigencia impide el desarrollo de lo que se ha denominado como una «concepción imperialista» del derecho a la libertad religiosa en la jurisprudencia de Estrasburgo, que tutele todas las manifestacio-

${ }^{34}$ Vid. J. F. Flauss, «Actualité de la Convention europèene des droits de l'homme», Actualité juridique du Droit Administrative, 2000, pp. 1015-1016.

${ }^{35}$ Vid. M. De SALVIA, «Liberté de Religion, esprit de tolérance et laïcité dans la jurisprudence de la Cour européenne des droits de l'homme», en Libertés, Justice, Tolérance, Mélanges en hommage au Doyen Gérard Cohen-Jonathan, Bruselas, 2004, p. 59; Véase en este sentido A. GARCía URETA, «La libertad de pensamiento de conciencia y de religión», en El Convenio Europeo de Derechos Humanos, op. cit., pp. 329 y ss. 
nes exteriores de la religiosidad. Una limitación que puede considerarse definitoria del marco de tratamiento jurídico de la religión a nivel europeo. La jurisprudencia, en este sentido, es relativamente amplia desde la década de los noventa y recoge supuestos en los que se puede apreciar el complejo equilibrio que ha de mantener el Juez de Estrasburgo entre la garantía del derecho -consustancial al pluralismo-, y el respeto al margen de apreciación de las autoridades nacionales para establecer las medidas necesarias que regulen ese pluralismo dentro de un determinado contexto democrático ${ }^{36}$.

De las sentencias condenatorias dictadas por el Tribunal por violaciones del artículo 9 de la Convención, son aquellas que tienen su origen en demandas fundadas en la ingerencia estatal en la autonomía religiosa de las confesiones las que han definido de forma más nítida el vínculo entre la libertad religiosa protegida por el Convenio, con la garantía del pluralismo y el principio de neutralidad del Estado. El principal exponente de esta jurisprudencia puede ser el affaire Serif c. Grecia ${ }^{37}$, en el cual, el Tribunal estimó que la condena impuesta por usurpación de funciones públicas a un ministro musulmán apoyado por buena parte de su comunidad religiosa, pero que no había sido elegido conforme al procedimiento previsto por la ley estatal, constituía una ingerencia en la libertad religiosa que violaba el artículo 9 de la Convención. Resulta interesante ver cómo la defensa del Estado griego alegaba que garantizar la unidad en la dirección espiritual de un grupo religioso, podía constituir dentro de su margen de apreciación nacional una medida necesaria en el seno de una sociedad democrática, para comprobar como el Tribunal, pese a reconocer que «las tensiones amenazan con aparecer cuando una comunidad religiosa u otra se divide», traza un límite nítido al ámbito de ingerencia estatal permitido, al señalar que las tensiones en el seno de las comunidades religiosas constituye «una de las consecuencias inevitables del pluralismo», subrayando que el papel del Estado no puede legítimamente consistir «en eliminar la causa de las tensiones suprimiendo el pluralismo, sino en velar para que los grupos concurrentes se toleren los unos a los otros». Por ello, la condena del que había ejercido como ministro de culto con el apoyo de parte de la comunidad religiosa no debía considerarse conforme al Convenio en tanto ésta no respondía a «una necesidad social imperiosa». Otro supuesto representativo de esta lógica es la sentencia Hassan et

\footnotetext{
${ }^{36}$ Atendiendo al recorrido por el cual la Corte de Estrasburgo transita hasta esta protección del «perfil bajo» durante la década de los noventa, véase A. GARAY, «La liberté religieuse en Europe-restriction et protection», Conscience et liberté, n. ${ }^{\circ}$ 59, 2000.

37 TEDH Serif c. Grèce, 14 de diciembre 1999; de similares características es la sentencia del caso Agga v. Greece, en el cual el Tribunal condena al Estado griego, al entender que había vulnerado el artículo 9 del Convenio con la condena por usurpación de funciones pública, a un Muftí elegido libremente por sus fieles que había rehusado a apartarse del cargo cuando el Estado griego había designado a otro religioso para él TEDH 17 de octubre de 2002 .
} 
Chaush c. Bulgarie $e^{38}$. En esta ocasión, se condena la destitución en sus funciones por parte del Estado del «Gran Mufti» que había sido elegido por sus fieles para el cargo. El Tribunal nuevamente insiste en que «la autonomía de las comunidades religiosas es indispensable al pluralismo en una sociedad democrática, y se encuentra en el corazón mismo de la protección ofrecida por el artículo 9»; y rechaza la idea de que en una sociedad democrática sean necesarias medidas que aseguren que las comunidades religiosas estén agrupadas bajo una autoridad eclesial unificada ${ }^{39}$.

El margen de intervención del Estado en el pluralismo, por lo tanto, queda limitado como consecuencia de esa obligación de neutralidad a la que hemos calificado por su intensidad como débil, pero que, como mínimo, excluye «toda apreciación por parte del Estado sobre la legitimidad de las creencias religiosas o sobre las modalidades de expresión de éstas» ${ }^{40}$.

En relación con esto, y aunque los supuestos vistos no sean del todo asimilables, nos parece necesario reflexionar brevemente, y no sin cierta anticipación, sobre los límites que en el ámbito del Convenio Europeo pudieran afectar a las tentativas estatales, calificadas por algunos autores de «galicanistas», de llevar a cabo una política de cultos encaminada a unificar y designar de forma oficial los interlocutores con el Estado de la religión islámica. Esta cuestión se lleva planteando de forma reiterada en Francia, dado el número de ciudadanos que profesan la religión islámica en el país, y la fragmentación existente en el seno de esta comunidad ${ }^{41}$. Las dificultades reales para articular un diálogo cooperativo entre el Estado y la confesión islámica hacen que distintos autores, e incluso el actual presidente de la República Nicolas Sarkozy, hayan sugerido la necesidad de replantear la estrictas limitaciones que impone la laicidad francesa al Estado, a la hora de regular el estatuto jurídico de las confesiones y establecer relaciones con ellas. Debe

${ }^{39}$ TEDH Hassan et Chaush c. Bulgarie, 26 de octubre 2000.

${ }^{39}$ Podemos ver un examen detallado de esta jurisprudencia, en el exhaustivo trabajo de M. J. GutiérRez del Moral y M. A. Cañivano Salvador, El Estado frente a la libertad de religión: jurisprudencia constitucional española y del Tribunal Europeo de Derechos Humanos, pp. 89-97; J. MARTínEZ TORRÓN, «La protección de la libertad religiosa en el sistema de Consejo de Europa», Protección nacional e internacional de la libertad religiosa, Madrid, 2001, pp. 110 y ss., o A. SEgLERs GómEZ-QuinTERo, La laicidad y sus matices, Granada, 2005, pp. 105-110.

${ }^{40}$ Vid. Iglesia Metropolitana de Besarabia c. Moldavia, 13 de diciembre de 2001. En la línea de los casos vistos, en esta ocasión el Tribunal entendió que las autoridades moldavas habían vulnerado el artículo 9 del Convenio al no reconocer a una Iglesia ortodoxa desvinculada de la Iglesia ortodoxa mayoritaria en el país, todo ello con el objetivo, según la defensa del Estado, de no lacrar uno de los elementos básicos de cohesión nacional.

${ }^{41}$ Vid. por todos, B. BASDEVAN-GAUDEMET, «Le statut juridique de l'Islam en France», en Revue de droit public, n. ${ }^{\circ}$ 2, 1996, pp. 355-385. 
señalarse que el interés por articular canales «oficiales» de comunicación con el islam en Francia no se justifica únicamente como una proyección del principio del Estado social en el ámbito de la libertad religiosa, de cara a facilitar las condiciones de ejercicio del derecho paliando las necesidades materiales que padece la comunidad islámica; sino, a su vez, en la necesidad de impedir que dentro del estricto marco de separación que impone la ley de separación de 1905, pueda consolidarse un aislamiento comunitario en determinadas partes del país que ponga en peligro el orden público, o el propio pacto republicano. Desde esta perspectiva, nos parece que, en ciertas circunstancias, la necesidad de políticas estatales que faciliten un diálogo con las confesiones, a través del reconocimiento estatal de sus interlocutores, puede ser contemplada legítimamente por parte de los Estados, sin que ello tenga que significar una ingerencia en la autonomía de las confesiones prohibida por el Convenio, o la trasgresión del principio de neutralidad del Estado. La estimación del margen de apreciación nacional y el juicio de proporcionalidad de las medidas, muy probablemente estarán llamados en el futuro a ser los criterios encargados de matizar o perfilar la jurisprudencia del Tribunal en materia de autonomía confesional, determinando una vez más la línea de la intervención estatal permisible ${ }^{43}$.

Como hemos podido ver en los casos anteriores, la afirmación de la libertad religiosa y la autonomía confesional frente al Estado es sinónimo de garantía del pluralismo, uno de los valores consustanciales a la sociedad democrática. Sin embargo, el Tribunal, desde el inicio, ha tenido presente que en un contexto de diversidad religiosa necesariamente se requiere una regulación estatal que discipline el ejercicio de las distintas manifestaciones del derecho ${ }^{44}$. Una regulación a la que pueden ir aparejadas determinadas ingerencias, cuando, como es sabido, éstas disfruten de cobertura legal, tengan un fin legítimo según el Convenio, sean necesarias en una sociedad democrática ${ }^{45}$. En la práctica, como destaca la doctrina, «la necesidad de la

${ }^{42}$ Véanse en este sentido las propuestas de reformulación de la laicidad francesa, hacia una laicidad positiva, que proponía el presidente de la República francesa en el libro $L a$ République, les religions, l'espérance. Entretien avec Thibaud Collin et le père Verdin, París, 2004.

${ }^{43}$ Véase también sobre este punto: O. Monguin et J. L. Schlegel, «Les questions de 1905», p. 91; J. MoRANGE, «Peut-on réviser la loi de 1905?», Revue Française du Droit Administrative, n. ${ }^{\circ}$ 1, Janvier-Février, 2005, p. 212.

${ }^{44}$ Más aun el Tribunal ha considerado que es un deber impuesto al Estado asegurar que los grupos opuestos se toleren. TEDH Parti communiste unifié de Turquie et autres c. Turquie, 30 de enero 1998.

${ }^{45}$ Vid. J. Brage CAMAZANo, «Aproximación a una teoría general de los derechos fundamentales en el Convenio Europeo de Derechos Humanos», Revista Española de Derecho Constitucional, n. ${ }^{\circ}$ 74, Mayo-Agosto, 2003, pp. 126 y ss. La aplicación de esta doctrina en la jurisprudencia del artículo 9 dictada por el Tribunal es examinada por A. DEBET, en «Signes Religieux et jurisprudence européenne», op. cit., pp. 221-247. 
medida» dentro de la jurisprudencia del Tribunal, está estrechamente ligada «al margen de apreciación nacional» y al mismo «principio de proporcionalidad» ${ }^{46}$, hasta el punto de que pueden considerarse como partes integrantes y entremezcladas de un mismo parámetro de juicio ${ }^{47}$.

Sin duda, los supuestos paradigmáticos de limitación a las manifestaciones de la libertad religiosa han procedido de las decisiones del Tribunal sobre la interdicción de signos y vestimentas religiosas en el ámbito público: el denominado «problema del velo». Una jurisprudencia que ha adquirido especial relevancia al amparo del debate suscitado en Francia, en torno a la aplicación del principio republicano de laicidad.

Ya durante los trabajos de la comisión convocada por el presidente francés Jacques Chirac, para la reflexión sobre las exigencias concretas que el principio de laicidad impone en la escuela republicana, la «Commision Stasi», el vicepresidente aquel entonces del TEDH, Jean Paul Costa, pudo poner en conocimiento de los miembros de la Comisión, la laxitud del Tribunal europeo en estos supuestos, dejando claro que una eventual ley que prohibiese el uso de signos y vestimentas religiosas en la escuela republicana, no se consideraría contraria al Convenio Europeo por el TEDH, ya que ésta sería enjuiciada necesariamente conforme al modelo francés de laicidad ${ }^{48}$.

La opinión del juez partía de que, en el ámbito de aplicación del Convenio, ya se había entendido legítima en virtud del principio de laicidad, y como «medida necesaria en una sociedad democrática», la restricción de determinadas formas de exteriorización de las creencias religiosas en las instituciones públicas ${ }^{49}$. Para encontrar la primera de estas decisiones, hemos de

${ }^{46}$ A pesar de su irrevocable vocación casuística, este principio goza de una minuciosa y compleja construcción dogmática. A buen seguro en nuestra doctrina una de las principales si no la principal referencia sobre esta materia se encuentra en la obra de C. BERNAL PULIDO, El principio de proporcionalidad y los derechos fundamentales, Madrid, 2003.

${ }^{47}$ Vid. J. BRAge CAMAZANO, «Aproximación a una teoría general de los derechos fundamentales en el Convenio Europeo de Derechos Humanos», op. cit., p. 126; J. GARcía RocA, «La muy discrecional doctrina del margen de apreciación nacional según el Tribunal Europeo de Derechos Humanos: soberanía e integración», op. cit., p. 4. Debe de subrayarse que solamente la manifestación, o exteriorización de estas libertades, puede ser objeto de limitación, siendo incoercible, en cualquier circunstancia, la dimensión interna de la libertad religiosa. En este sentido, como ha dejado claro el Tribunal, a diferencia de los artículos 8,10 , y 11 , cuyo segundo párrafo engloba todos los aspectos del derecho mencionados en el artículo, el segundo párrafo del artículo 9 sólo y expresamente alcanza a la manifestación del derecho. TEDH Kokkinakis c. Grecè, 25 de mayo 1993.

${ }^{48}$ Vid. Le Monde el 28 de octubre de 2003 «Le Vice-Président de la Cour Européene de droits de l'homme se déclare favorable à une loi», de $\mathrm{Ph}$. Bernard.

${ }^{49}$ Incluso en un contexto distinto y especialmente alejado del modelo laico de Estado, la jurisprudencia del Tribunal Europeo de Derechos Humanos ha respaldado al Reino Unido, al considerar que no suponía una ingerencia en el derecho a la libertad religiosa la obligación impuesta a un profesor de respetar las horas de trabajo, a pesar de que éstas correspondan con sus horas de oración (ComEDH X c. Reino Unido 12 de marzo de 1981); la obliga- 
remontarnos a dos asuntos, Karaduman c. Turquía y Balut c. Turquía, en los cuales, la antigua Comisión Europea de Derechos Humanos entendió que no existía una ingerencia en la libertad religiosa prohibida por el Convenio, por el hecho de que la Universidad turca exigiese a dos alumnas musulmanas, como condición para certificar sus estudios académicos, y dentro del marco general de restricciones al uso de vestimentas religiosas establecido por la universidad pública, una fotografía en la que éstas apareciesen despojadas de su foulard $^{50}$. Trece años después, en Araç c. Turquia, el Tribunal se enfrentará de nuevo a un supuesto de características casi idénticas. Se trataba igualmente de una alumna universitaria turca, a la que esta vez se le exigía para formalizar su inscripción una fotografía en la que apareciese con el rostro descubierto. En esta ocasión, será el Tribunal y por unanimidad, el que determine la inadmisión de la demanda, en una decisión que podría considerarse previsible, si se toma en consideración que en el período de tiempo que media entre ambos litigios, el TEDH había ido consolidando una doctrina jurisprudencial particularmente generosa con aquellas cauciones legislativas tomadas por los Estados para garantizar la neutralidad de las instituciones públicas, y sobre todo, con los esfuerzos de la autoridades de un país mayoritariamente musulman como Turquía para velar por la continuidad de la laicidad de sus instituciones, y luchar contra el fundamentalismo religioso. Puede citarse en este sentido, la sentencia Kalac c. Turquie, en la cual el Tribunal, por unanimidad, estimó que en aras de proteger la neutralidad de las fuerzas armadas en Turquía, un país donde el ejército, junto a la magistratura, ha ejercido de principal defensor de la laicidad del Estado, no podía considerarse una ingerencia en la libertad religiosa prohibida por el artículo 9 del Convenio, la relegación a la reserva de un militar turco, cuando su comportamiento y sus actos revelaban que éste había adoptado opiniones religiosas fundamentalistas ${ }^{51}$.

toriedad de usar el casco cuando se conduce un ciclomotror, incluso cuando esto entra en conflicto con uso de atuendos propios de su religión, en este caso la religión Sikh (ComEDH Xc. Reino Unido 12 de julio de 1978); o la denegación a unos reclusos de su petición de sustituir sus vestimentas penitenciarias por las vestimentas propias de su confesión religiosa.

${ }^{50}$ ComEDH Karaduman c. Turquie \& Balut c. Turquie, 3 de mayo 1993. En ambas decisiones la Comisión alude al legítimo interés de las autoridades turcas de evitar que el fundamentalismo religioso lesione el orden público de las instituciones educativas del Estado, y de que en un país donde la mayoría de los ciudadanos profesa la religión musulmana, la manifestación de los ritos de esta religión pueda constituir un elemento de presión para aquellos estudiantes que no la practiquen o pertenezcan a otra religión.

51 TeDH Kalac c. Turquie, 1 de julio 1997. Esta permisividad del tribunal ha tenido sus límites, y la jurisprudencia ha tenido ocasión de ser menos indulgente con las medidas de control del fundamentalismo religioso en la República Turca. A este respecto, y atendiendo al contexto particular, el Tribunal ha entendido que las opiniones integristas en contra de la laicidad y la democracia y a favor de la instauración de un régimen fundamentado en la «Charia», vertidas durante un programa televisivo, no podían ser objeto de sanción, tomando en consideración el formato polémico de la emisión, la inmediatez de la opinión y su carácter exclusivamente oral. TEDH, Müslüm Gündüz c. Turquie, 4 de diciembre 2003. 
Otra de las decisiones más relevantes dentro de este período jurisprudencial proviene de un conflicto que tiene como protagonista a un país como Suiza que, por lo menos en la actualidad, parece ajeno a conflictos religiosos de gran magnitud. Se trata del conocido asunto Mme. Dahlab c. Suisse ${ }^{52}$, en el cual el Tribunal hubo de considerar si, en el cuadro de su actividad profesional, prohibir a una maestra convertida al islam cubrir su rostro con un foulard durante las clases vulneraba lo dispuesto en el artículo 9 del Convenio, o si bien, esta medida restrictiva de su libertad religiosa podía entenderse dentro del margen de apreciación del país, como necesaria en una sociedad democrática, para lograr un fin legítimo como es garantizar la neutralidad religiosa de la escuela pública, el respeto a la libertad religiosa de los alumnos, e incluso, la paz religiosa. El Tribunal no llegará a dictar sentencia sobre el asunto, desestimando la admisión de la demanda. Un aspecto relevante de esta decisión se encuentra en el hecho de que la argumentación usada por parte del Tribunal para justificar la adecuación al Convenio de la actitud del Estado no sólo versa sobre los argumentos contextuales o pragmáticos reiterados por los tribunales suizos, como la importancia del principio de laicidad en el Cantón de Ginebra o su consagración en la Constitución Federal; sino que va más allá de las circunstancias concretas que determinaban el margen de apreciación nacional, y apela al respeto a valores fundamentales del Convenio, aludiendo a las dificultades existentes a la hora de conciliar el uso obligatorio por parte de las mujeres de una prenda como el foulard islámico con el mensaje de tolerancia, de respeto a los otros, y sobre todo de igualdad y no discriminación que en una democracia todo maestro ha de tener hacia sus alumnos ${ }^{53}$. Con esta apelación a los valores democráticos europeos, el Tribunal no deja de señalar una coincidencia axiológica entre el orden público nacional oponible a determinadas manifestaciones de la libertad religiosa por parte de los agentes públicos en el Estado laico, y los valores protegidos por el Convenio. Esta superación del horizonte contextual a la hora de argumentar sobre la adecuación al Convenio de determinadas ingerencias en el derecho a la libertad religiosa en contextos caracterizados por la vigencia de principios como el de neutralidad o laicidad del Estado,

52 TEDH Dahlab c. Suisse, 15 de febrero 2001.

${ }^{53}$ Vid. M. LEVINET en su artículo, «L'incompatibilité entre l'Etat théocratique et la Convention européene des droits de l'homme. A propos de l'arrêt le 13 de février 2003 par la Cour de Strasbourg dans l'affaire Refah Partisi et autres c/ Turquie», Revue Françoise du droit constitutionnelle, n. ${ }^{\circ}$ 57, 2004, pp. 207 y ss.; L. MARTíN-RETORTILLO BAQUER, La afirmación de la libertad religiosa en Europa: de guerras de religión a meras cuestiones administrativas, Madrid, 2006, pp. 65-69; J. F. FLAuss, «Laïcité et Convention Européenne des droits de l'homme», Revue du Droit Public et de la Science Politique en France et a l'Entranger, n. $^{\circ} 120,2004$, pp. 320-321. Debe de señalarse que el Tribunal ya había vinculado con anterioridad la neutralidad religiosa con la garantía del pluralismo educativo «esencial para la preservación de una sociedad democrática». Vid. Kjeldsen, Buskmadsen y Pedersen c/ Danemark, 7 de diciembre 1976. 
desembocará, a raíz de la controvertida disolución del «Partido de la Prosperidad» turco, en lo que muchos autores han considerado una verdadera alusión al principio de laicidad, no ya como un modelo particular y contextual de garantía de la aconfesionalidad del Estado, sino como uno de los valores comunes y fundamentales subyacentes al Convenio.

\section{La laicidad elevada a valor del Convenio Europeo de Derechos Huma- nos. ¿Qué laicidad?}

En el conocido caso Refah Partisi et autres c. Turquie, primero la Sala y luego la Gran Sala del Tribunal europeo determinaron la convencionalidad de la disolución judicial de un partido político en Turquía. A pesar de que esta jurisprudencia fue en su momento examinada con detalle y comentada en nuestra doctrina ${ }^{54}$, expondremos brevemente los pormenores de un asunto al que irremediablemente hemos vuelto la vista en los últimos meses a raíz de las actuaciones judiciales emprendidas por las autoridades turcas contra la formación política actualmente en el poder, el Partido de la justicia y del desarrollo (AKP) de Recep Tayip Erdogan, por considerar a esta agrupación un «foco de actividades antilaicas». Otro episodio más de la difícil relación entre los tribunales turcos y el derecho de asociación política, y de los partidos políticos turcos con los valores republicanos ${ }^{55}$, que en esta ocasión, gracias al pragmatismo de la mayoría de jueces del constitucional, no terminó con la disolución de una formación política que en las elecciones de 2007 fue amparada por el $47 \%$ de los votantes ${ }^{56}$.

${ }^{54}$ Vid. entre otros J. GARCía RocA, «La problemática disolución del partido de la prosperidad ante el Tribunal Europeo de Derechos Humanos: Estado constitucional y control de las actividades del partidos fundamentalistas», Revista Española de Derecho Constitucio$n a l,{ }^{\circ}{ }^{\circ} 65,2002$; A. BARRERO ORTEGA, «Reapertura del debate democracia abierta v. democracia militante en la jurisprudencia del Tribunal Europeo de Derechos Humanos», en $L a$ prohibición de partidos políticos, Almería, 2004, pp. 185-204; LORENZO MARTín RETORTILLO, «El problema de las aspiraciones religiosas incompatibles con el sistema democrático. ¿Se justifica la disolución de un partido político que las auspicia?», Revista de Estudios de Derecho Europeo, 2 (2002), 337 y ss.; sobre la incidencia de la doctrina del Tribunal europeo en el derecho de partidos patrio, véase la reciente monografía de M. IGLESIAS BAREZ, La ilegalización de partidos políticos en el ordenamiento jurídico español, Granada, 2008, en especial, pp. 250 y ss.

${ }^{55}$ En Turquía se han ilegalizado 24 partidos en los últimos 50 años. Véase el espacio dedicado a Turquía en el Informe Semanal de Política Exterior, de 4 de agosto de 2008, p. 3.

${ }^{56}$ El AKP es sin duda un partido extraño. Algunos politólogos lo han calificado como un OVNI político por su compleja transversalidad en el seno de la sociedad turca, a través de un discurso que engloba el liberalismo económico y el europeísmo al mismo tiempo que el conservadurismo y el islamismo moderado, propio de sus principales dirigentes, los cuales han hecho de la legalización del uso del velo en el ámbito publico una particular batalla, que una vez más ha inquietado al establishment laico. Así, el gobierno anuló la ley que pro- 
El perfil general del asunto Partido de la Prosperidad contra Turquía no era, ni mucho menos, ajeno al Juez de Estrasburgo, quien en cuatro ocasiones anteriores ya había resuelto sobre la adecuación al Convenio de la disolución de un partido político por parte de las autoridades turcas, condenando en todas ellas al Estado por la vulneración del derecho de asociación política consagrado en el artículo 11 de la Convención ${ }^{57}$. Ahora bien, dos circunstancias hacían diferente este supuesto con respecto a los anteriores. La primera era que el Refah Partisi contaba en el momento de su ilegalización con una importante legitimación democrática. Se trataba del primer partido en número de votos y escaños en el parlamento turco ${ }^{58}$, una mayoría parlamentaria que le había permitido formar gobierno en coalición con el partido de centro derecha «La Justa Voz». Esta circunstancia incrementaba el carácter -si se me permite la expresión- «contramayoritario» de la disolución llevada a cabo en esta ocasión por las autoridades turcas, aunque también, por otro lado, hacía que la posibilidad de que el partido pudiese realizar sus aspiraciones políticas inconstitucionales se convirtiese en una amenaza real y cierta a los ojos del juzgador ${ }^{59}$.

El segundo elemento distintivo lo constituía el hecho de que, en este caso, la amenaza para el régimen democrático turco representada por el partido tenía su origen en las aspiraciones partidistas de naturaleza y origen religiosos, que transcendían de las actuaciones públicas y declaraciones hechas por sus dirigentes, las cuales, al parecer de las autoridades judiciales del Estado, constituían un peligro para la vigencia de su principio de laicidad. Un principio elevado a lo más alto de la jerarquía normativa en la Constitución del país, intangible frente a cualquier procedimiento de reforma constitucional, y que, a la luz de la experiencia histórica turca, constituye uno de los pilares básicos sobre los que se consolida el tránsito de la teocracia otomana, al sistema constitucional y democrático que - no sin sus matices- rige en esta República de población mayoritariamente musulmana ${ }^{60}$.

hibía a las mujeres portar el velo a las universidades, un acto que tuvo la rápida respuesta del Constitucional, que anuló la decisión restableciendo la vigencia de la prohibición. Esta y otras actuaciones dieron lugar a un proceso de ilegalización del partido por actividades contrarias al principio de laicidad, finalmente abortado por el Tribunal Constitucional. Vid. Mark SEmo, «Turquie: la contra-offensive des Kémalistes», Politique Internationale, 2008, pp. 217-233.

${ }^{57}$ Se trata de los asuntos Parti Comuniste unifié de Turquie et autres c. Turquie, 30 de enero de 1998; Parti Socialista de Turquie et autres c. Turquie, 25 de mayo 1998; Parti de la Liberté et de la Democratice (ÖZDEP) c. Turquie, 8 de diciembre 1999; y Parti du Travail du Peuple et autres c. Turquie, 9 de abril 2002.

${ }^{58}$ En concreto, disponía de 158 escaños de los 450 de la Asamblea Nacional.

${ }^{59}$ Vid. J. GARCíA RocA, «La problemática disolución del partido de la prosperidad ante el Tribunal Europeo de Derechos Humanos: Estado constitucional y control de las actividades del partidos fundamentalistas», op. cit., p. 297.

${ }^{60}$ A. BARRERO ORTEGA, «Reapertura del debate democracia abierta v. democracia militante en la jurisprudencia del Tribunal Europeo de Derechos Humanos», op. cit. pp. 187-188. 
En concreto, tres fueron los objetivos políticos manifestados por los dirigentes de la formación que el Tribunal Constitucional turco consideró como una amenaza real para la laicidad del Estado y con ello para la democracia del país. El primero era la aspiración de implantar un sistema multijurídico, en el que se determinara el estatuto de derechos y obligaciones de los ciudadanos en función de la comunidad religiosa a la que perteneciesen. En segundo lugar, el Tribunal Constitucional turco justificaba la disolución en la voluntad manifestada por los dirigentes del partido de aplicar la ley islámica, la «Sharia», a las relaciones jurídicas entre musulmanes, y, como derecho común, a las relaciones entre éstos y los no pertenecientes a la confesión islámica. Finalmente, el tercero de los propósitos considerados para justificar la necesidad de la disolución fue la determinación declarada o de alguna forma hecha pública por parte de los dirigentes del partido de recurrir, en virtud de la doctrina islámica de la «Yihad» o «guerra santa», a la violencia como método para conservar el poder y realizar sus objetivos políticos ${ }^{61}$.

El TEDH consideró las acusaciones según las cuales las autoridades turcas apoyaban su decisión de disolver el partido político, entendiendo con el Tribunal Constitucional turco que estas aspiraciones resultaban radicalmente contrarias a un régimen democrático de libertades, único posible en el ámbito del Convenio, por atentar contra valores sustantivos que se encuentran en el corazón de este modelo político como la igualdad, el Estado de derecho, o el mismo respeto por la integridad física de las personas. A la hora de ponderar la necesidad social imperiosa de la ingerencia en el derecho de asociación política y su proporcionalidad, el Tribunal valoró el hecho de que, dada la posibilidad real de que el Refah Partisi ostentara el poder político, la amenaza de que sus aspiraciones se vieran realizadas no era una mera conjetura improbable. En segundo lugar, como ya había realizado en otras ocasiones, el Tribunal consideró el contexto nacional histórico y, concretamente, las particulares dificultades que, desde que fue fundada por Kemal Atatürk en 1923, ha debido de afrontar Turquía para consolidar una república democrática y secularizada. Un contexto en el que la defensa del principio de laicidad del Estado posee una importancia trascendental para el sostenimiento de las instituciones democráticas, que justifica para el TEDH la ingerencia que habían realizado las autoridades turcas en el derecho de asociación política.

Pero desde la perspectiva de las relaciones entre el Estado y las religiones en el ámbito del Convenio Europeo, lo que llama la atención de la sentencia Refah Partisi es que el énfasis del Tribunal a la hora de justificar la restricción en la defensa del principio de laicidad del Estado no se reduce a

${ }^{61}$ Vid. M. LEVINET en su artículo, «L'incompatibilité entre l'Etat théocratique et la Convention européene des droits de l'homme. A propos de l'arrêt le 13 de février 2003 par la Cour de Strasbourg dans l'affaire Refah Partisi et autres c/ Turquie», op. cit., pp. 209 y ss. 
subrayar la importancia de este principio y de su vigencia en el ordenamiento jurídico y las instituciones turcas, sino que el Juez de Estrasburgo, más allá de afirmar su relevancia en el contexto nacional para la ponderación de los bienes jurídicos en conflicto, proclama la relación consustancial entre el principio de laicidad y el núcleo axiológico del propio Convenio. En este sentido, y parafraseando al poeta Gil de Biedma, puede decirse que finalmente, en la sentencia Refah Partisi, lo que sólo parecía ser las dimensiones del teatro turco (el estado laico) en realidad acaba siendo el argumento de la obra europea. Dice el Tribunal:

«el principio de laicidad es seguramente uno de los principios fundadores del Estado que responden a la preeminencia del derecho y al respeto de los derechos del hombre y la democracia».

En definitiva, a la luz de la sentencia Refah Partisi, parece ser que para el TEDH, la laicidad no es sólo un principio que los Estados pueden consagrar en su ordenamiento jurídico para regir sus relaciones con las confesiones, en armonía con su historia política, o con las necesidades que imponga la gestión jurídica de su pluralidad religiosa, sino que es uno de los pilares de los que no puede disponer el sistema democrático de libertades que garantiza el Convenio. Tal y como ha afirmado Garay, el Estado laico es asumido por el Juez de Estrasburgo «no ya de un modo contextual como laicidad a la francesa o a la turca», sino como una suerte de «laicidad cultural, que formaría parte de una concepción de la sociedad democrática según la cual el Estado de Derecho, justamente porque garantiza la libertad de religión, es el lugar para situar y limitar las manifestaciones externas del fenómeno religioso» ${ }^{62}$. Y parece que en este sentido, como señalaba Jean François Flauss, este pronunciamiento constituye «el punto de partida de una jurisprudencia que consolida la laicidad como parte de los valores y principios que integran el orden público material europeo oponible» ${ }^{63}$, e incluso como uno de los «componentes del patriotismo de la Convención» ${ }^{64}$.

Observamos a este respecto que dentro del Tribunal, se produce la aporía de que a partir de una jurisprudencia en un principio tendente a permitir un amplio margen de apreciación nacional en lo referido a la relación del Esta-

${ }^{62}$ Vid. A. GARAY, «La laïcité, principe érigé en valeur de la Convention Européene des droits de l'homme», Le Dalloz, París, n. ${ }^{\circ}$ 2, 12 janvier 2006, pp. 103 y ss. A este respecto véanse las páginas 106-108. Véase en el mismo sentido J. ROBERT, «Les relations des Églises et de L'Etat en Europe», op. cit., p. 30.

${ }^{63}$ Vid. J. F. Flauss, «Actualité de la Convention europpenne des droits de l'homme», Actualité Juridique Droit Administrative, junio, 2003, p. 610.

${ }^{64} \mathrm{Vid}$. J. F. Flauss, «Laïcité et Convention Européenne des droits de l'homme», p. 319. 
do con el fenómeno religioso, termina consolidándose la laicidad del Estado como un valor integrante de los principios necesarios en la sociedad democrática europea, como el respeto a las libertades de los otros y la preeminencia del derecho. Esta suerte de «europeización del derecho de las religiones» en torno a la laicidad y a través de la jurisprudencia del TEDH acomoda sin duda los modelos de laicidad francesa o turca en el ámbito europeo dentro de una jurisprudencia que apuesta por la primacía de lo jurídico sobre las diferencias culturales y religiosas ${ }^{65}$. A su vez, el recurso al término «laicidad» por parte del Tribunal, aun en defecto de una mención explícita de éste en el Convenio, ampliaría el cuadro jurídico del orden público europeo ${ }^{66}$, el cual, como es sabido, no sólo está compuesto por los derechos y libertades sino también por los valores comunes fundamentales recogidos en el preámbulo del Convenio ${ }^{67}$.

En este sentido, como ha señalado la doctrina, el asunto Refah Partisi afianza a través de su afirmación de laicidad la doctrina jurisprudencial que el Tribunal había elaborado en aplicación del artículo 9, confirmando que las libertades de pensamiento, de conciencia y de religión, no son desde el punto de vista jurídico una suerte de derechos atrappe tout. Como destaca Flauss, esta jurisprudencia deja claro que el Convenio de derechos no puede

${ }^{65}$ Vid. J. F. FLauss, «Actualité de la Convention europpenne des droits de l'homme», op. cit., p. 611.

${ }^{66}$ La expresión «orden público europeo» fue usada por primera vez por la Comisión en 1962 en el asunto Austria c. Italia, con posterioridad el Tribunal acuñó su alcance en el asunto Temeltasch 18 de enero de 1978 Irlanda c. Reino Unido, en donde afirma que «el Convenio, a diferencia de los tratados internacionales de tipo clásico, desborda el ámbito de aplicación de la mera reciprocidad entre los Estados contratantes. Además de una red de compromisos sinalagmáticos bilaterales, crea unas obligaciones objetivas, las cuales disfrutan de una garantía colectiva», desde entonces el Tribunal se ha referido al Convenio como un «instrumento constitucional de orden público europeo». Vid. A. QueRALT JiMENEZ, El Tribunal de Estrasburgo: Una jurisdicción internacional para la protección de los derechos fundamentales, Valencia, 2003, pp. 68-70. Es particularmente interesante el estudio realizado desde la filosofía del derecho por el profesor Álvarez Ortega, sobre la progresiva convergencia hacia una unidad axiológica entre el concepto de orden público europeo y el de los Estados miembros de la Unión. En él ofrece una tentativa de definición que merece la pena ser transcrita literalmente: «Orden público debe entenderse como el núcleo axiológico inderogable de un ordenamiento que recoge su eticidad específica y concreta y se halla defendido por un pluralidad de mecanismos técnicos. El recurso al orden público supone, en todo el ordenamiento, una quiebra importante de valores esenciales interrelacionados y configurantes del ethos de una sociedad determinada; una quiebra originada por una retorsión en el normal funcionamiento de las normas que arroja un resultado intolerable que trata de evitarse mediante la ponderación de los bienes jurídicos y derechos en juego en cada caso concreto». Vid. M. Álvarez OrTEGA, «Orden público: unidad axiológica y espacio europeo», Anuario de derecho europeo, n. ${ }^{\circ}$ 3, 2003, p. 43.

${ }^{67}$ Vid. P. Rolland, «Ordre public et practiques religieusses», J. F. Flauss (ed.), La protection internationale de la liberté religieuse, Bruselas, 2002. 
ser un instrumento de confort personal. Cualquier concepción hipertrofiada de la diversidad cultural tendrá como límite la laicidad en tanto «principio fundador del Estado», a través del cual se garantizan la libertad religiosa y la preeminencia del derecho ${ }^{68}$.

La deducción realizada por la jurisprudencia de Estrasburgo del principio de laicidad del Estado puede leerse como una apuesta por un modelo de integración del pluralismo religioso, lejano del relativismo axiológico, en el cual el ejercicio del derecho a la diferencia está sometido a la asunción no sólo de los procedimientos de la democracia, sino también de los valores que la sustentan. Usando la terminología «berliniana», el Tribunal Europeo de las libertades ha asumido en gran medida la aporía liberal de que el orden de libertades europeo también conlleva pérdidas y excluye formas de vida ${ }^{69}$, y en última instancia, el Convenio Europeo de Derechos humanos, como regulación jurídica de carácter objetivo y vinculante, ha de servir para delimitar los límites de la tolerancia. La defensa de la laicidad y el pluralismo, consecuencia tanto del deber de neutralidad del Estado como de una estimación positiva de la heterogeneidad social y el disenso, parece una orientación valorativa adecuada para una jurisprudencia de vocación necesariamente integradora no sólo de distintas realidades nacionales, sino también de una comunidad política multicultural, en la que conviven ciudadanos cuyo equipaje metafísico es muy dispar. La afirmación de estos principios por la jurisprudencia del TEDH refuerza sin duda la vigencia del orden europeo, al mismo tiempo que, como ha señalado algún autor, realiza una necesaria labor pedagógica -e integradora- delimitando el terreno de lo permisible en democracia $^{70}$. Desde esta perspectiva, a pesar de que la sentencia pueda ofrecer dudas y resulte siempre problemática la asimilación en el ámbito del Consejo de Europa de determinadas patologías de la rígida «tutela democrática» que imponen los tribunales, y, por qué no decirlo, el ejército en Turquía, Refah Partisi es una sentencia justamente celebrada en Europa.

Ahora bien, la proclamación de la «laicidad» en el Convenio requiere ser tomada con ciertas cautelas y matices. En primer lugar, debe de señalarse que el «bilingüismo» del Tribunal no alcanza en esta ocasión a dotar de

\footnotetext{
${ }^{68}$ Concretamente, para el autor, en el ámbito del derecho internacional privado, el principio de laicidad está llamado a jugar un papel relevante, como parte integrante del orden público material oponible a las resoluciones extranjeras que consagren o apliquen normas discriminatorias fundadas sobre principios religiosos. La vigencia del principio de laicidad nace de la esperanza de que por fin «sea el gran momento en que el orden público europeo de los derechos del hombre territorialice plenamente las normas de derecho internacional privado aplicables a la determinación del estatuto personal de los individuos». J. F. FLAuss, «Actualité de la Convention europpenne des droits de l'homme», op. cit., p. 611.

${ }^{69}$ I. Berlin, El fuste torcido de la Humanidad, Barcelona, 2002.

${ }^{70} \mathrm{Vid}$. A. GARAY, «L'Islam et l'ordre public européen vus par la Cour européenne des droits de l'homme», en Revue du droit internacional et de droit comparé, Bruselas, 2005.
} 
coherencia al tratamiento del concepto. «Laïcité» no es «Secularism». Como ha señalado algún autor, en unos tiempos en los que pocas palabras se resisten a la «anglicización», que la «laïcité» sigue siendo un concepto singularmente francés ${ }^{71}$, recibido en otros ordenamientos jurídicos, generalmente en países de tradición católica, donde se afirma como principio jurídico por lo común a partir de una operación de exégesis constitucional, con los matices propios que impone tanto la convivencia con otros principios constitucionales, como la especial permeabilidad a los factores históricos o sociológicos que caracteriza a la regulación jurídica de las relaciones entre el Estado y las religiones. La laicidad surge históricamente a través de un proceso inflexivo y de ruptura que supone la desconfesionalización de la estructura estatal, mientras que el secularismo hace alusión a otro proceso más progresivo y dinámico, propio de los países de tradición protestante, en el cual se afirma de forma paulatina la libertad religiosa en la sociedad, pero sin que ello implique necesariamente una ruptura paralela de los vínculos institucionales históricos entre el Estado y la Iglesia nacional ${ }^{72}$.

En buena lógica, y tomando en consideración la necesaria vocación integradora de su jurisprudencia, el TEDH no puede apelar al principio de laicidad con su significado político originario, ya que éste sería incompatible con buena parte de los modelos de relación Iglesia-Estado vigentes en el ámbito del Convenio. Por este motivo, se señala que el Tribunal no alude al valor de la laicidad como una «laicidad a la francesa», sino como una «laicidad cultural». Esta «laicidad cultural» es una laicidad de contenido mínimo o esencial, pero, al mismo tiempo, consustancial a la cultura política común de los Estados: la democracia liberal. El Convenio hace de la laicidad un valor europeo en tanto se opone a todo modelo de Estado o sociedad organizado según reglas religiosas -es decir, a la teocracia- y protege la igual libertad de las personas independientemente de sus convicciones religiosas. Esto significa que los Estados están legitimados por el Convenio para tomar medidas contra determinados intentos de deslaicización del ámbito público, como aquellos dirigidos a implantar un derecho de origen religioso, estático e inmutable, por encima del propio principio de soberanía popular y del Estado de derecho; o a estratificar jurídicamente a los ciudadanos en función de sus creencias religiosas, rompiendo el concepto jurídico de ciudadanía. Ni la libertad religiosa, ni la libertad de asociación política amparan ninguna de estas conductas.

Por otro lado, hay que señalar que la laicidad es una cualidad que se predica del Estado y de sus instituciones, no del ciudadano ni de la sociedad. En el Estado laico, las instituciones públicas y sus agentes han de mantener una

71 Vid. J. BAuberot y E. Poulat, Laïcité, Enciclopedia universales, 2002, vol. 13, pp. 257-262.

${ }^{2}$ Vid. F. ChAmpion, «Entre laïcisacion et secularisation. Des rapports Église-État dans l'Europe communautaire», op. cit., pp. 46 y ss. 
actitud de escrupulosa neutralidad religiosa, pero ninguna obligación de neutralidad religiosa se impone a los ciudadanos en virtud del principio de laicidad del Estado. Precisamente el Estado laico nace con la modernidad política de la propia separación liberal entre Estado y sociedad civil ${ }^{73}$. El Estado no reconoce, prohíbe ni promociona ningún culto, y las religiones «compiten» en el seno de la sociedad sin ninguna intervención por parte del Estado. La única limitación que impone el principio de laicidad al ciudadano es que éste no puede imponer por sí mismo, ni pretender imponer a través del aparato estatal, su verdad religiosa a una persona, ni a la comunidad. En este sentido, la laicidad es también como se ha dicho «un principio activo contra toda la forma de opresión de la conciencia de los individuos, provenga ésta de las instituciones públicas o de las comunidades religiosas» ${ }^{74}$. Sin duda, ésta es la gran lección que nos recuerda a los europeos el TEDH en la sentencia Refah Partisi.

En este sentido, es cuestionable que la imposición de restricciones en el ámbito de las instituciones públicas a la libertad religiosa de los ciudadanos se justifique según el principio de laicidad. Ésta ha sido por motivos muy precisos la solución turca, y desde el 2004, también la solución francesa en relación con el problema del velo en las escuelas, donde la obligación de neutralidad de los funcionarios y agentes públicos se ha trasladado a los usuarios del servicio basándose en la misma lógica del principio de laicidad del Estado. En mi opinión, esto supone una reformulación, en cierto modo ideologizada, del principio de laicidad francés que no casa con la construcción jurídica liberal que la doctrina y el Consejo de Estado han hecho de este principio. Aun así, esto es discutible, y en el caso francés, la composición y el rigor de los trabajos de la Comisión cuyo informe dio origen a la ley invitan por lo menos a reflexionar sobre la necesidad de la medida con cierta cautela. Sin embargo, lo que no es discutible es que, el significado de la laicidad en el ámbito del Convenio no puede mimetizarse con las dos soluciones contextuales turca y francesa. La laicidad no puede ser un principio que absorba, legitimándolas en nombre de la convención, las limitaciones a la manifestación del derecho a la libertad religiosa.

Otra cosa distinta es que, dado que en el juicio sobre la convencionalidad de estas restricciones es crucial el contexto de la prohibición y el margen de apreciación del Estado, el hecho de que la laicidad sea interpretada en países como Turquía o Francia como una condición necesaria para la integración de su pluralismo religioso, la paz religiosa o la educación en los valores de la República... puede determinar un juicio afirmativo sobre la adecuación al Convenio de medidas que suponen una ingerencia en la libertad

${ }^{73}$ Vid. M. BARBIER, «Esquise d'une théorie de la laïcité», Le Debat, n. ${ }^{\circ}$ 77, 1994.

${ }^{74}$ Vid. G. KouBI, «La laïcité sans tolerance», Revue de la Recherche Juridique, 1994, n. ${ }^{\circ}$, p. 722 . 
religiosa como la de prohibir el uso del velo en las aulas estatales a las alumnas musulmanas ${ }^{75}$. No está de más recordar que, en muchos de los Estados europeos, aún es frecuente encontrar simbología religiosa, concretamente crucifijos, en las aulas de la escuela pública. Ciertamente, en este contexto donde la laicidad escolar parece no constituir una necesidad democrática para el Estado, una legislación limitativa del uso de simbología religiosa por parte de los alumnos según el propio principio de laicidad sería no sólo un contrasentido, sino también una evidente e impermisible discriminación religiosa ${ }^{76}$.

El TEDH tuvo la oportunidad de trazar una distinción entre el principio de laicidad que puede considerarse consustancial a los valores democráticos protegidos por el Convenio, y el concepto jurídico de laicidad que al amparo de un singular contexto histórico y cultural es aplicado por los jueces turcos, en el asunto Leyla Sahin c. Turquie ${ }^{77}$. En este caso, otra vez la Sala y la Gran Sala del Tribunal hubieron de sentenciar si la interdicción del uso del foulard a una alumna musulmana de la universidad pública turca, justificada según el principio de laicidad del Estado, vulneraba o no el artículo 9 del Convenio.

Como en anteriores ocasiones, el Tribunal, a la hora de valorar la necesidad de la medida, subraya el importante margen de apreciación del que disfrutan las autoridades nacionales en este ámbito, y destaca las diferentes tradiciones existentes en Europa en lo que se refiere al tratamiento jurídico de la religión, para posteriormente singularizar el contexto turco con deteni-

\footnotetext{
${ }^{75}$ Así lo entiende Martín Retortillo, quien afirma que «no en cualquier parte, ni en cualquier circunstancia, pero la defensa de bienes jurídicos tan señalados como la neutralidad de unas instituciones, o la laicidad en todos los escalones del Estado, en aquellos sistemas que se los toman en serio, justifican sobradamente ciertas restricciones en lo que sería el desarrollo normal de la libertad religiosa, como que no se haga alarde de una concreta opción religiosa a través, por ejemplo, de determinados símbolos o atuendos». Vid. L. MARTín-RETORTILlo BAQUeR, «La afirmación de la libertad religiosa en Europa: de las guerras de religión a meras cuestiones administrativas», op. cit., p. 89.

${ }^{76} \mathrm{Vid}$. en este sentido, no es extraño que como demuestran diversos estudios, la línea general mantenida en Espora en relación con el uso de simbología religiosa en el ámbito escolar es la permisión, salvo en aquellos supuestos específicos en los cuales su uso pueda impedir el desarrollo de normal de las actividades escolares, o la identificación del alumno. En este sentido es interesante ver cómo la polémica sentencia de un Tribunal de Apelación Británico Shabina Begum v. Head Teacher adn Governors of Denbigh High School (2004), en la cual se declara que la expulsión de una alumna de su centro educativo por negarse a despojarse de la jilbad había constituido una violación de la libertad religiosa, al tomar en consideración el asunto Sahin v. Turquía, señala la relevancia del contexto jurídico en el que se aplica la medida restrictiva. El Tribunal destaca en este sentido que «existen consideraciones dignas de apreciación por un Estado cuya Constitución profesa el valor del secularismo que no resultan necesariamente aplicables a Reino Unido». Citamos el caso y tomamos la traducción, a partir del artículo de M. FrAILE ORTIZ, «Algunas actuaciones de las autoridades europeas sobre el uso del velo islámico en el ámbito educativo», Cuadernos de Derecho Público, n. ${ }^{\circ}$ 24, Enero-Abril, 2005, p. 219.

${ }^{77}$ TEDH Leyla Sahin c. Turquie 10 de noviembre 2005.
} 
miento, a través de un recorrido histórico por la vida de la República desde su fundación. Todo lo cual le sirve al Juez de Estrasburgo para poner nuevamente de manifiesto la condición basilar del principio de laicidad en la democracia turca, y las exigencias que requiere en su contexto político y cultural la garantía de los derechos de terceros y del principio de igualdad de sexos. No se olvida tampoco de destacar la presencia en Turquía de movimientos fundamentalistas e integristas, y el necesario margen que han de tener las autoridades turcas para tomar las medidas necesarias contra estos movimientos. Hasta aquí, de acuerdo. Pero en su argumentación, la sentencia alude, de forma desconcertante, a dos precedentes Dahlab c/ Suiza y Refah Partisi c/ Turquía, que distan de ser semejantes al que enjuiciaba la Corte en esta ocasión y que enturbian, sin duda, la lógica del Tribunal. Con respecto al primero, coincidimos con Lasagabaster en la improcedencia de la analogía trazada por el Tribunal ${ }^{78}$. La diferencia crucial en nuestra opinión es que en Dahlab c/Suiza se trataba de una maestra de la escuela pública la que había visto restringida su libertad religiosa, al impedírsele durante las clases el uso del foulard. Al tratarse de un funcionario público, y más aún en el ámbito escolar, donde, como bien apreciaba el Tribunal, un signo fuerte de pertenencia religiosa puede tener impacto sobre alumnos de corta edad, las exigencias derivadas del principio de neutralidad del Estado se imponen de una forma singular ${ }^{79}$. La vinculación de un funcionario público al principio de neutralidad estatal, o al propio principio de laicidad, no es de ninguna manera asimilable a la de un alumno universitario. Recordemos que la laicidad es un principio que vincula al Estado, precisamente para que los ciudadanos puedan ser libres -y con ello no neutrales- en su religiosidad. Más confusas aún resultan las continuas alusiones del Tribunal a la sentencia Refah Partisi, un supuesto donde, como hemos visto, la laicidad se afirmaba frente a las tentativas de suplantación del Estado de derecho, la ruptura del concepto jurídico de ciudadanía y la incitación a la violencia como método político. ¿Es esto asimilable al uso de vestimentas o símbolos religiosos en el ámbito público? Ciertamente no. Con la alusión al asunto Refah Partisi, el Tribunal parece darnos a entender que el principio de laicidad consustancial a la cultura de la democracia, y que proclamaba como uno de los pilares fundadores del Estado de derecho, es sin más y en abstracto oponible a una manifestación de la libertad religiosa, como es el uso de foulard

${ }^{78}$ I. LAGASABASTER Herrarte, «El velo islámico en la universidad turca. Nota a la sentencia del Tribunal Europeo de Derechos Humanos de 29 de junio de 2004, Sahin c. Turquía», Revista Vasca de Administración Pública, núm. 70, 2004, pp. 392; igualmente crítica en este sentido es M. FraILE OrTIZ, «Algunas actuaciones de las autoridades europeas sobre el uso del velo islámico en el ámbito educativo», op. cit., p. 220.

${ }^{79}$ Vid. por todos, la monografía de P. LANGERON, Liberté de conscience des agents publics et laïcité, París, 1996. 
islámico en el ámbito de una institución del Estado. Esta me parece una senda errónea ${ }^{80}$.

La laicidad como principio que legitima las restricciones a las manifestaciones de libertad religiosa no es común a la cultura democrática europea, sino que es propia de un contexto muy determinado y excepcional como el turco. El Tribunal debe entonces plantearse la compatibilidad del modelo de laicidad turco con el Convenio, y hacerlo a la luz de la Historia y en función de las particulares circunstancias en las que las autoridades de ese país han ejercer su función de «organizador neutro e imparcial» del pluralismo religioso, garantizando el orden público, la paz religiosa y la tolerancia en una sociedad democrática. Ahora bien, esto no le exime, como bien señala la juez Tulknes en su voto particular, de una ponderación de los bienes en conflicto y un juicio sobre la proporcionalidad de la medida. Es decir, que el margen de apreciación nacional no puede agotar el juicio sobre «la necesidad social imperiosa», ni más ni menos porque el derecho a la libertad religiosa «no es una cuestión local en el ámbito del Convenio». En definitiva, la necesaria y generosa colaboración de Estrasburgo con los esfuerzos de las autoridades turcas para consolidar una democracia secularizada, no puede desembocar en una devaluación del perfil garantista de la doctrina del Tribunal sobre el derecho a la libertad religiosa, dentro de una jurisprudencia que por distintas exigencias realistas ha sido cuanto menos timorata. En Leyla Sahin c. Turquía, el Tribunal, en mi opinión, afirmó de una manera prudente y acertada la compatibilidad de modelo de laicidad turca con el Convenio, pero no ofreció la argumentación necesaria para justificar en el supuesto concreto la proporcionalidad de la ingerencia en el derecho a la libertad religiosa.

\section{A modo de conclusión}

En el seno de una jurisdicción de necesaria vocación integradora, que asume el pluralismo y donde las tradiciones jurídicas de los Estados miembros han de ser respetadas, al preguntarnos, en relación con los modelos de relación Iglesia-Estado presentes en su ámbito de jurisdicción, si debe avan-

\footnotetext{
${ }^{80}$ Igualmente críticos con el razonamiento y el fallo de la Gran Sala, Eugenia Relaño y Alain Garay destacan esta ambigüedad o imprecisión en el acercamiento al concepto jurídico de laicidad por parte del Tribunal en los siguientes términos: «... para evitar un análisis pormenorizado del caso presente y del contenido del concepto de laicidad, el Tribunal opta por confirmar el concepto de laicidad mantenido en el caso Refah Partisi sin considerar si, esta vez, la interpretación de la laicidad ofrecida por las autoridades turcas puede llegar a vulnerar los derechos del Convenio. La simple mención reiterada y general del concepto de laicidad por el Tribunal no debe obstaculizar un debate riguroso sobre el contenido de la laicidad turca», vid. E. RElaÑo PASTOR y A. GARAY, «Los temores del Tribunal Europeo de Derechos Humanos al velo islámico: Leyla Sahin c. Turquía», Revista General de Derecho Canónico y Eclesiástico del Estado, n. ${ }^{\circ}$ 12, 2006, pp. 17-18 (citamos las páginas por la versión del artículo colgada en la página $<$ www.iustel.com $>$ ) Este artículo también se encuentra publicado en la Revista Europea de Derechos Fundamentales, n. ${ }^{\circ}$ 6, 2006.
} 
zarse hacia su armonización, o bien respetar las opciones nacionales, la única respuesta sensata es que el Tribunal debe tomarse en serio la protección de la libertad religiosa. Tiene razón el Juez de Estrasburgo cuando afirma la imposibilidad de una comprensión unívoca del rol de la religión en la sociedad europea, e igualmente, son evidentes las importantes diferencias existentes en el ámbito de las relaciones Iglesia-Estado entre los países miembros del Consejo de Europa, y la geometría variable de principios constitucionales como el de laicidad. Esto, unido a la lógica de la subsidiariedad, hace que la única forma en la cual puede proclamarse la laicidad como parte integrante del orden público europeo sea, tal y como hizo la Gran Sala en la sentencia Refah Partisi, aludiendo a su sentido mínimo o esencial, como un laicidad inherente a la cultura democrática de los europeos, que se concretaría en la preeminencia del derecho, la igualdad en el estatuto del ciudadano independientemente de su religión, y el necesario respeto a los derechos fundamentales en la manifestación de la libertad religiosa. Aun así, no debemos olvidar la Historia de nuestro continente, y cómo ésta ha puesto de manifiesto que existe un nexo lógico -y cronológico- entre la separación de la Iglesia y el Estado y la garantía real de la libertad religiosa más allá de la mera tolerancia ${ }^{81}$. Si la jurisprudencia del Tribunal Europeo de Derechos Humanos toma en serio la libertad religiosa, y toma en serio la dimensión igualitaria de este derecho ${ }^{82}$, esto, sin duda, irá de la mano de una afirmación más enérgica de los dos componentes del principio de laicidad del Estado, la separación entre el Estado y las confesiones, y la neutralidad religiosa ${ }^{83}$. En este sentido, la efectividad de una armonización exigente del canon europeo de protección de la libertad religiosa pasa necesariamente, tanto por una revisión de los residuos de privilegio confesional que perviven en muchos Estados parte del Convenio, como por un control menos condescendiente de las reformulaciones coyunturales o contextuales del principio de laicidad, extremadamente restrictivas del derecho a la libertad religiosa.

${ }^{81}$ Vid. G. PeCES-BARBA, Tránsito a la modernidad y Derechos Fundamentales, Madrid, 1982, pp. 25-123.

${ }^{82}$ Vid. A. BARRero OrTega, La libertad religiosa en España, op. cit., pp. 137 y ss.

${ }^{83}$ En este sentido coincidimos con Pablo Santaolaya, quien reflexionando sobre el impacto que pudiese tener la consagración del derecho a la libertad religiosa en la Constitución Europea, señalaba que «cualquier diferencia de estatus entre confesiones religiosas debe estar en condiciones de superar este test, y probablemente muchas de las cosas que hoy hemos visto considerar dentro del margen nacional de apreciación no podrán continuar siéndolo en el futuro. Sólo así será posible hablar de la libertad religiosa como derecho fundamental de los europeos. Parece, por tanto, que se puede apuntar de una tendencia a la progresiva construcción de un concepto unitario de la libertad religiosa en Europa, que necesariamente vendrá unido a la expansión del derecho a la laicidad». Mi único desacuerdo con el autor es que, en mi opinión, el principio de laicidad define la actitud del Estado hacia el fenómeno religioso, y no admite su comprensión como un derecho subjetivo. Vid. P. SANTAOLAYA, «Sobre el derecho a la laicidad (Libertad religiosa e intervención de los poderes públicos)», op. cit., p. 66. 